\title{
"ITÔ's LEMMA" AND THE BELLMAN EQUATION FOR PoISSON PROCESSES: AN APPLIED VIEW
}

\author{
KEN SENNEWALD \\ KLAUS WAELDE
}

\author{
CESIFO WORKING PAPER NO. 1684 \\ CATEGORY 10: EMPIRICAL AND TheORETICAL MethodS \\ MARCH 2006
}

An electronic version of the paper may be downloaded

- from the SSRN website:

www.SSRN.com

- from the CESifo website:

www.CESifo-group.de 


\title{
“ITÔ'S LEMMA" AND THE BELLMAN EQUATION FOR POISSON PROCESSES: AN APPLIED VIEW
}

\begin{abstract}
Using the Hamilton-Jacobi-Bellman equation, we derive both a Keynes-Ramsey rule and a closed form solution for an optimal consumption-investment problem with labor income. The utility function is unbounded and uncertainty stems from a Poisson process. Our results can be derived because of the proofs presented in the accompanying paper by Sennewald (2006). Additional examples are given which highlight the correct use of the Hamilton-JacobiBellman equation and the change-of-variables formula (sometimes referred to as "Ito'sLemma") under Poisson uncertainty.
\end{abstract}

JEL Code: C61, D81, D90, G11.

Keywords: stochastic differential equation, Poisson process, Bellman equation, portfolio optimization, consumption optimization.

\author{
Ken Sennewald \\ Ifo Institute for Economic Research \\ Einsteinstr. 3 \\ 01069 Dresden \\ Germany \\ ken.sennewald@tu-dresden.de
}

\author{
Klaus Waelde \\ Department of Economics \\ University of Würzburg \\ 97070 Würzburg \\ Germany \\ Klaus@Waelde.com
}

March 1, 2006

We are indebted to two anonymous referees for very constructive comments. 


\section{Introduction}

Poisson processes as a source of uncertainty are a standard tool for modeling rare and randomly occurring events. These processes can be found, among others, in quality-ladder models of growth (e.g., Grossman and Helpman, 1991, Aghion and Howitt, 1992, 1998), in the endogenous fluctuations and growth literature with uncertainty (e.g., Wälde, 2005, Steger, 2005), in the labor market matching literature (e.g., Moen, 1997), in monetary economics (e.g., Kiyotaki and Wright, 1991), and in finance (e.g., Merton, 1971). In most cases Poisson processes affect the concerned variables through a stochastic differential equation $(S D E)$. The two "major tools" required when working with SDEs are the change-of-variables formula $(C V F)$, as a "rule" for computing the differential of functions of stochastic processes, and, in so far as optimal control is concerned, the Hamilton-Jacobi-Bellman (HJB) equation. ${ }^{1}$

CVFs for SDEs driven by Poisson processes are provided by many textbooks in economics. They might, however, be inappropriate for the use in economic modeling. As will be discussed in detail at the end of Subsection 2.1, they either apply to one-dimensional processes with only one source for jump uncertainty or they do not provide the exact stochastic differential after a mapping. Sennewald (2006) presents therefore a CVF that can be applied on mappings of multidimensional SDEs with many Poisson processes and that leads to the exact differential.

Despite the widespread use, applying the HJB equation as a necessary or sufficient criterion for optimality has required so far a set of restrictive or simplifying assumptions. In particular, the boundedness of the instantaneous utility (or cost) function and of the coefficients in the constraint, which is given as a SDE, has been in most cases indispensable for the use of the HJB equation as a necessary criterion, see, e.g., Gihman and Skorohod (1972) or Dempster (1991). Other authors as, e.g., Kushner (1967) require, instead of this boundedness condition, the value function to be contained in the domain of the infinitesimal generator of the controlled process. ${ }^{2}$ However, both conditions are not convenient for economic modeling since, on the one hand, in most cases neither utility and cost functions nor the constraint's coefficients are bounded and, on the other, to check whether the value

\footnotetext{
${ }^{1}$ Some readers may know the CVF better under the term Ito's lemma and the HJB equation under the name Bellman equation, which are the corresponding notations for frameworks with Brownian motion.

${ }^{2}$ The domain of the infinitesimal generator of a process $X(t)$ consists of all once continuously differentiable function $V$ for that the $\operatorname{limit}_{\lim _{h \searrow 0}}\left[E_{t} V(X(t+h))-V(X(t))\right] / t$ exist.
} 
function belongs to the mentioned domain requires in general a lot of calculation. To solve this problem, Sennewald (2006) shows that the HJB equation can still be used as a necessary criterion for optimality if, instead of boundedness, only linear boundedness is assumed. ${ }^{3}$ Apart from a terminal condition, no boundedness condition is required at all for deriving the sufficiency of the HJB equation.

The present paper accompanies the rigorous proofs in Sennewald (2006) and is directed at the applied model builder. It presents examples for the application of CVF and the HJB equation. These examples should allow to work with Poisson uncertainty in other setups as well. Both papers have the intention to encourage a more widespread use of Poisson processes under more general assumptions concerning the economic environment.

After presenting versions of CVF in the subsequent section, we provide some applications for it: A derivation of a household's budget constraint and of a HJB equation for an optimumconsumption problem. In Section 3 we present a typical maximization problem, consisting in determining a household's optimal consumption and investment behavior in the presence of a deterministic flow of labor income. We use the HJB equation to derive both a KeynesRamsey rule and a closed form solution. Based on that result, we provide through a mean preserving spread a concise discussion on how uncertainty affects the expected consumption growth and distinguish between the precautionary saving and reallocation mechanism. The quantitative effect of either mechanism is stated explicitly. A simple method how to achieve a mean preserving spread in a Poisson setting is presented as well.

The maximization problem in Section 3 extends a "standard" optimum consumption and portfolio problem as considered by, e.g., Merton (1969, 1971) and Aase (1984) by allowing for labor income in a Poisson framework. Merton (1971) derives a solution including wages when uncertainty of the risky investment is modeled by Brownian motion. Aase (1984) extends Merton's model by introducing random jumps. But even though he gives hints on how to proceed if wages as an additional source of income are taken into account, no solution for this case is presented.

Keynes-Ramsey rules have been derived before, e.g., by Cass (1965) and Koopmans (1965) in a deterministic growth model, by Turnovsky (2000) in a model of stochastic growth with

\footnotetext{
${ }^{3}$ Note that, if the value function is sufficiently smooth, the boundedness assumptions are sufficient for the value function to be in the domain of the infinitesimal generator. Sennewald (2006) shows implicitly that this property holds also for the more general case with linearly bounded utility and coefficients.
} 
Brownian motion, by Steger (2005) in an $A K$-type growth model with jumps, or by Wälde (1999b) for an optimum-consumption problem similar to the one presented here. There are two crucial differences compared to Wälde (1999b). First, Wälde focuses on risky R\&D which implies a return of minus one when R\&D is not successful. We follow the "tradition" of Merton and assume that the risky asset yields at least a certain deterministic return. Second and crucial for results, we allow for two assets, a risky and a riskless one. The KeynesRamsey rule for this setup impressively demonstrates the simplifying nature of allowing for a second asset: While in one-asset cases the Keynes-Ramsey rule contains terms which are hard to work with (the derivative of consumption with respect to wealth - the marginal propensity to consume out of wealth - for Brownian motion or the post-jump consumption level for Poisson uncertainty), this is not the case when there is a second asset. The postjump consumption level can here be expressed as a function of current consumption and parameters. Consumption jumps are therefore known and the Keynes-Ramsey rule becomes as straightforward to work with as deterministic Keynes-Ramsey rules.

This Keynes-Ramsey rule shows that increasing uncertainty always reduces average, i.e. expected consumption growth. In a two-asset model of growth with Brownian motion as noise, Obstfeld (1994) arrives at a similar result. In an $A K$ model of growth with Poisson uncertainty, Steger (2005) finds that the response of the average consumption growth on higher risk is ambiguous and depends on the household's risk aversion. We reconcile Steger's with Obstfeld's findings: Steger's one-asset case only induces a precautionary saving effect. In our setup with two assets, the reallocation effect always dominates the precautionary savings effect.

\section{Change of Variables Formula ("Ito's Lemma")}

This section first presents various versions of CVF, which is a "rule" for computing the differential of functions of stochastic processes, and includes a discussion why other CVFs presented by standard textbooks as, e.g., Malliaris and Brock (1982), might not be appropriate for the use in economic modeling. The second and third subsection provide typical applications of the CVF by showing how the budget constraint of a household can be derived via CVF. The fourth subsection shows how the HJB equation for a simple household's maximization problem is heuristically obtained, also by using CVF. 


\subsection{A proposition and three corollaries}

In the following we deal with one- or multidimensional stochastic processes $x(t)$ that, starting at time $t_{0}$ in $x\left(t_{0}\right)$, obey SDEs of the form

$$
d x(t)=\alpha(t, x(t)) d t+\sum_{k=1}^{m} \beta_{k}\left(t, x\left(t_{-}\right)\right) d q_{k}(t), \quad x\left(t_{0}\right) \in \mathbb{R}^{n},
$$

where $\alpha, \beta_{1}, \ldots, \beta_{m}:[0, \infty) \times \mathbb{R}^{n} \rightarrow \mathbb{R}^{n}$ are non-stochastic continuous vector functions and $q_{1}, \ldots, q_{m}$ independent Poisson processes starting at $t_{0}>00^{4,5}$ The process $x(t)$ is a so called cádlág process. The expression cádlág is an acronym from the french "continu a droite, limites a gauche". That is, the paths of $x(t)$ are continuous from the right with left limits. The left limit is denoted by $x\left(t_{-}\right) \equiv \lim _{s \uparrow t} x(s)$. Thus, due to the continuity of the $\beta_{k}$, the left limit of $\beta_{k}(t, x(t))$ is given by $\beta_{k}\left(t, x\left(t_{-}\right)\right)$. At first glance, it might appear strange that one uses the left limit $\beta_{k}\left(t, x\left(t_{-}\right)\right)$instead of $\beta_{k}(t, x(t))$ as integrand in SDE (1). But beyond analytical reasons, there is a simple intuitive explanation why this should be like this. When a Poisson process $q_{k}(t)$ jumps, i.e., $d q_{k}(t)=1$, then $x(t)$ jumps from $x\left(t_{-}\right)$to $x(t)$, where the jump size is given by $\beta_{k}$. It would not make much sense if the jump size depended on the post-jump state $x(t)$. It is rather convenient to assume that the jump size is determined by the state just before the jump occurs — which is formally $x\left(t_{-}\right)$. Thus, the jump size itself is then given by $\beta_{k}\left(t, x\left(t_{-}\right)\right)$.

Our main statement on CVF, presented in the following proposition, is taken from Sennewald (2006, Theorem 1).

Proposition 1 (Multidimensional stochastic process) Consider the $n$-dimensional stochastic process $x(t)=\left(x_{1}(t), \ldots, x_{n}(t)\right)^{T}$ following SDE (1). That is, each component obeys

$$
d x_{i}(t)=\alpha_{i}(t, x(t)) d t+\sum_{k=1}^{m} \beta_{i k}\left(t, x\left(t_{-}\right)\right) d q_{k}(t), \quad i=1, \ldots, n
$$

where $\alpha_{i}, \beta_{i k}:[0, \infty) \times \mathbb{R}^{n} \rightarrow \mathbb{R}$. For a once continuously differentiable function $f:[0, \infty) \times$

$$
{ }^{4} \text { The differentials have to be read componentwise, i.e., } \beta_{k}\left(t, x\left(t_{-}\right)\right) d q_{k}(t)=\left(\begin{array}{c}
\beta_{1 k}\left(t, x\left(t_{-}\right)\right) d q_{k}(t) \\
\vdots \\
\beta_{n k}\left(t, x\left(t_{-}\right)\right) d q_{k}(t)
\end{array}\right) \text {. }
$$

${ }^{5}$ A detailed analysis of SDEs with Poisson processes can be found in, e.g., Protter (1995) and Garcia and Griego (1994). 
$\mathbb{R}^{n} \rightarrow \mathbb{R}$, the differential of the process $f(t, x(t))$ is given by

$$
\begin{aligned}
d f(t, x(t))= & {\left[f_{t}(t, x(t))+\sum_{i=1}^{n} f_{x_{i}}(t, x(t)) \alpha_{i}(t, x(t))\right] d t } \\
& +\sum_{k=1}^{m}\left[f\left(t, x\left(t_{-}\right)+\beta_{k}\left(t, x\left(t_{-}\right)\right)\right)-f\left(t, x\left(t_{-}\right)\right)\right] d q_{k}(t),
\end{aligned}
$$

where $f_{t}$ and $f_{x_{i}}, i=1, \ldots, n$, denote the partial derivatives of $f$ with respect to $t$ and $x_{i}$, respectively, and $\beta_{k}$ stands as in SDE (1) for the $n$-dimensional vector function $\left(\beta_{1 k}, \ldots, \beta_{n k}\right)^{T}$.

Intuitively speaking, the differential of a function is given by the "normal terms", i.e., the partial derivatives with respect to its first argument $t$ and with respect to $x_{1}, \ldots, x_{n}$ times changes per unit of time ( 1 for the first argument and $\alpha_{i}(t, x(t))$ for each component $x_{i}$ ) times $d t$, and by a "jump term". Whenever a process $q_{k}(t)$ jumps, each $x_{i}$ increases by the $\beta_{i k}\left(t, x\left(t_{-}\right)\right)$, and the function jumps thus from $f\left(t, x\left(t_{-}\right)\right)$to $f(t, x(t))=$ $f\left(t, x\left(t_{-}\right)+\beta_{k}\left(t, x\left(t_{-}\right)\right)\right)$.

The cádlág property of $f(t, x(t))$ holds trivially for all continuous functions $f$, and we therefore do not mention it anymore in the following corollaries.

Corollary 1 (A deterministic and a stochastic differential with many independent Poisson processes $q_{k}(t)$ ) Consider two one-dimensional processes $x(t)$ and $y(t)$ given by the deterministic differential $d x(t)=\alpha_{x}(t, x(t), y(t)) d t$ and $S D E$

$$
d y(t)=\alpha_{y}(t, x(t), y(t)) d t+\sum_{k=1}^{m} \beta_{k}\left(t, x(t), y\left(t_{-}\right)\right) d q_{k}(t),{ }^{6}
$$

respectively. Then, for a once continuously differentiable function $f:[0, \infty) \times \mathbb{R}^{2} \rightarrow \mathbb{R}$, the process $f(t, x(t), y(t))$ follows

$$
\begin{aligned}
d f(t, x(t), y(t))=\left[\begin{array}{c}
f_{t}(t, x(t), y(t))+f_{x}(t, x(t), y(t)) \alpha_{x}(t, x(t), y(t)) \\
+f_{y}(t, x(t), y(t)) \alpha_{y}(t, x(t), y(t))
\end{array}\right] d t \\
+\sum_{k=1}^{m}\left[f\left(t, x(t), y\left(t_{-}\right)+\beta_{k}\left(t, x(t), y\left(t_{-}\right)\right)\right)-f\left(t, x(t), y\left(t_{-}\right)\right)\right] d q_{k}(t),
\end{aligned}
$$

where $f_{x}$ and $f_{y}$ stand for the partial derivatives of $f$ with respect to $x$ and $y$, respectively.

Again, the differential of $f$ is given by the "normal terms" and by a "jump term". Whenever any of the processes $q_{k}(t)$ jumps, $y(t)$ increases by $\beta_{k}\left(t, x(t), y\left(t_{-}\right)\right)$and the function jumps from $f\left(t, x(t), y\left(t_{-}\right)\right)$to $f\left(t, x(t), y\left(t_{-}\right)+\beta_{k}\left(t, x(t), y\left(t_{-}\right)\right)\right)$. Obviously, as $d x(t)$ has no jump term, $x(t)$ does not jump. The following corollary presents a twodimensional special case in which each component is driven by its "own" Poisson process.

\footnotetext{
${ }^{6}$ Observe that $x(t)$ possesses continuous paths and thus $x\left(t_{-}\right)=x(t)$.
} 
Corollary 2 (Two stochastic processes) Consider the one-dimensional stochastic processes $x(t)$ and $y(t)$ given by

$$
\begin{aligned}
& d x(t)=\alpha_{x}(t, x(t), y(t)) d t+\beta_{x}\left(t, x\left(t_{-}\right), y\left(t_{-}\right)\right) d q_{x}(t) \\
& d y(t)=\alpha_{y}(t, x(t), y(t)) d t+\beta_{y}\left(t, x\left(t_{-}\right), y\left(t_{-}\right)\right) d q_{y}(t) .
\end{aligned}
$$

For a once continuously differentiable function $f:[0, \infty) \times \mathbb{R}^{2} \rightarrow \mathbb{R}$, the process $f(t, x(t), y(t))$ obeys

$$
\begin{aligned}
d f(t, x(t), y(t))= & {\left[\begin{array}{c}
f_{t}(t, x(t), y(t))+f_{x}(t, x(t), y(t)) \alpha_{x}(t, x(t), y(t)) \\
+f_{y}(t, x(t), y(t)) \alpha_{y}(t, x(t), y(t))
\end{array}\right] d t } \\
& +\left[f\left(t, x\left(t_{-}\right)+\beta_{x}(\cdot), y\left(t_{-}\right)\right)-f\left(t, x\left(t_{-}\right), y\left(t_{-}\right)\right)\right] d q_{x}(t) \\
& +\left[f\left(t, x\left(t_{-}\right), y\left(t_{-}\right)+\beta_{y}(\cdot)\right)-f\left(t, x\left(t_{-}\right), y\left(t_{-}\right)\right)\right] d q_{y}(t),
\end{aligned}
$$

where we set $\beta_{i}(\cdot) \equiv \beta_{i}\left(t, x\left(t_{-}\right), y\left(t_{-}\right)\right), i=x, y$.

As before, the "normal terms" include the partial derivatives $f_{t}, f_{x}$, and $f_{y}$. Whenever, for example, Poisson process $q_{x}(t)$ jumps, the corresponding process $x(t)$ increases by $\beta_{x}\left(t, x\left(t_{-}\right), y\left(t_{-}\right)\right)$and the "jump term" makes the function jump from $f\left(t, x\left(t_{-}\right), y\left(t_{-}\right)\right)$ to $f\left(t, x\left(t_{-}\right)+\beta_{x}(\cdot), y\left(t_{-}\right)\right)$. When $q_{y}(t)$ jumps, only $y(t)$ increases. Observe that, even though $q_{x}(t)$ and $q_{y}(t)$ are independent, the differentials $d x(t)$ and $d y(t)$ and thus the processes $x(t)$ and $y(t)$ are in general not since the change of each process depends through $\beta_{i}$ on the other process.

In light of the preceding results one can see why CVFs from standard textbooks in economics may not be suitable for the applied model builder. First of all, most authors, such as Merton (1990), consider merely univariate processes with only one source of uncertainty, which may be insufficient as our example in Subsection 2.3 will show. Furthermore there are CVFs that yield only approximations of the differential $d f$. Malliaris and Brock (1982, Proposition 12.1 on p. 122) provide the expected difference $E \Delta f$ only, but not the exact observable $d f$. Another example is given in Dixit and Pindyck (1994), going back probably to a misprint. Readers should not be confused when comparing their CVF in Eq. (39) on p. 85 with our statements presented above. The exact expression in Dixit and Pindyck (1994), adapted to our notation, should read as stated in the following corollary. 
Corollary 3 (A single Poisson process) Consider a one-dimensional stochastic process $x(t)$ described by $d x(t)=\alpha(t, x(t)) d t+\beta\left(t, x\left(t_{-}\right)\right) d q(t)$. Then, for a once continuously differentiable function $f:[0, \infty) \times \mathbb{R} \rightarrow \mathbb{R}$, the differential of the process $f(t, x(t))$ reads

$$
\begin{aligned}
d f(t, x(t))= & {\left[f_{t}(t, x(t))+f_{x}(t, x(t)) \alpha(t, x(t))\right] d t } \\
& +\left[f\left(t, x\left(t_{-}\right)+\beta\left(t, x\left(t_{-}\right)\right)\right)-f\left(t, x\left(t_{-}\right)\right)\right] d q(t) .
\end{aligned}
$$

\subsection{Application I: The budget constraint}

Most maximization problems require a constraint. For a household, this is usually the budget constraint. We show here how the structure of the budget constraint depends on the economic environment the household finds itself in and how the CVF is used in this context.

Let wealth $a(t)$ at time $t$ be given by the number $n(t)$ of stocks a household owns times their price $v(t)$. That is, $a(t)=n(t) v(t)$. Let the price follow a process that is exogenous to the household (but potentially endogenous in general equilibrium),

$$
d v(t)=\alpha v(t) d t+\beta v\left(t_{-}\right) d q(t)
$$

Hence, the price grows with the continuous rate $\alpha \in \mathbb{R}$ and at discrete random times it jumps by $\beta$ percent. In order to avoid negative prices we assume $\beta>-1$. The random times are modeled by the jump times of a Poisson process $q(t)$ with arrival rate $\lambda$, which is the probability that in the current "period" a price jump occurs. The expected (or average) growth rate is then given by $\alpha+\lambda \beta$, cf. Appendix A.

Let the household earn dividend payments $\pi(t)$ per unit of asset and labor income $w(t)$. Let consumption expenditure be given by $p(t) c(t)$, where $c(t)$ denotes the consumption quantity and $p(t)$ the price of one unit of the consumption good. If buying stocks is the only way of saving, the number of stocks held by the household changes in a deterministic way according to

$$
d n(t)=\frac{n(t) \pi(t)+w(t)-p(t) c(t)}{v(t)} d t .
$$

When savings $n(t) \pi(t)+w(t)-p(t) c(t)$ are positive, the number of stocks held by the household increases by savings divided by the price of one stock. When savings are negative, the number of stocks decreases.

The change of the household's wealth, i.e., the household's budget constraint, is then obtained by applying CVF to $a(t)=n(t) v(t)$. Using Corollary 1 with $f(t, x, y)=x y$, we 
obtain

$$
\begin{aligned}
d a(t)= & {\left[v(t) \frac{n(t) \pi(t)+w(t)-p(t) c(t)}{v(t)}+n(t) \alpha v(t)\right] d t } \\
& +\left[n\left(t_{-}\right)\left[v\left(t_{-}\right)+\beta v\left(t_{-}\right)\right]-n\left(t_{-}\right) v\left(t_{-}\right)\right] d q(t) \\
= & {[r(t) a(t)+w(t)-p(t) c(t)] d t+\beta a\left(t_{-}\right) d q(t), }
\end{aligned}
$$

where the interest-rate is defined as $r(t) \equiv \pi(t) / v(t)+\alpha$. This is a very intuitive budget constraint: As long as the asset price does not jump, i.e., $d q(t)=0$, the household's wealth increases by current savings, $r(t) a(t)+w(t)-p(t) c(t)$, where the interest rate $r(t)$ consists of dividend payments in units of the asset price plus the deterministic growth rate of the asset price. If a price jump occurs, i.e., $d q(t)=1$, wealth jumps by $\beta$ percent, which is the stochastic part of the overall interest-rate.

\subsection{Application II: A two-sector economy}

This subsection presents a derivation of a household's budget constraint in a more complex economic environment. We thereby obtain a two-dimensional example for Corollary 2. Consider an economy consisting of two sectors employing technologies $X(t)=A(t) K_{X}^{\alpha}(t) L_{X}^{1-\alpha}(t)$ and $Y(t)=B(t) K_{Y}^{\alpha}(t) L_{Y}^{1-\alpha}(t)$ where $K(t)=K_{X}(t)+K_{Y}(t)$ is the economy's capital stock at time $t$ and $L=L_{X}(t)+L_{Y}(t)$ its constant labor force. The economy produces under perfect competition. Total factor productivity $(T F P)$ in both sectors is stochastic,

$$
\frac{d A(t)}{A\left(t_{-}\right)}=\psi_{A} d t+\gamma_{A} d q_{A}(t) \quad \text { and } \quad \frac{d B(t)}{B\left(t_{-}\right)}=\psi_{B} d t+\gamma_{B} d q_{B}(t)
$$

where the parameters $\psi_{i}$ and $\gamma_{i}$ are constant and such that $A(t)$ and $B(t)$ are non-decreasing in an expected sense, i.e., for any $\tau>t, E_{t} A(\tau) \geq A(t)$ and $E_{t} B(\tau) \geq B(t)$ where $E_{t}$ denotes throughout the paper the expectation conditional on time $t$. Given that capital and labor are instantaneously mobile across sectors, factor prices $w_{K}(t)$ for capital and $w_{L}(t)$ for labor are identical in both sectors. Thus, since technologies only differ in their TFP level, we find from the equality of prices with marginal costs that the relative price of goods reads

$$
\frac{p_{X}(t)}{p_{Y}(t)}=\frac{B(t)}{A(t)}
$$

Capital is the only asset in which households can save. Capital accumulation is governed by $d K(t)=[I(t)-\delta K(t)] d t$, where the investment good industry assembles the goods $X$ 
and $Y$ to obtain new production units, $I(t)=\Phi X_{I}^{\sigma}(t) Y_{I}^{1-\sigma}(t)$, given some constant $\Phi>0$. $X_{I}(t)$ and $Y_{I}(t)$ are the aggregate savings of the households in the goods $X$ and $Y$. When the investment good industry produces under perfect competition as well, the price of one unit of the investment good is, for a suitable choice of $\Phi$,

$$
p_{I}(t)=p_{X}^{\sigma}(t) p_{Y}^{1-\sigma}(t)
$$

We now choose good $Y(t)$ as numeraire. Real wealth of a typical household, measured in units of $Y(t)$, is then given by

$$
a(t) \equiv \frac{p_{I}(t) k(t)}{p_{Y}(t)}=\left(\frac{p_{X}(t)}{p_{Y}(t)}\right)^{\sigma} k(t)
$$

where $k(t)$ stands for capital per household. As in the previous example, the change in $k(t)$ is governed by the difference between income and consumption expenditure, divided by the price of capital,

$$
d k(t)=\frac{w_{K}(t) k(t)+w_{L}(t)-p_{X}(t) c_{X}(t)-p_{Y}(t) c_{Y}(t)}{p_{I}(t)} d t
$$

We can now compute the evolution of $a(t)$ by using CVF. With (5) and $(7), a(t)$ can be expressed by $a(t)=[B(t) / A(t)]^{\sigma} k(t)$. The differential of the TFP ratio $B(t) / A(t)$ is obtained by applying CVF from Corollary 2 on $f(x, y)=x / y$ and on the stochastic differentials in (4):

$$
d \frac{B(t)}{A(t)}=\left(\psi_{B}-\psi_{A}\right) \frac{B(t)}{A(t)} d t+\left(\frac{1}{1+\gamma_{A}}-1\right) \frac{B\left(t_{-}\right)}{A\left(t_{-}\right)} d q_{A}(t)+\gamma_{B} \frac{B\left(t_{-}\right)}{A\left(t_{-}\right)} d q_{B}(t) .
$$

Then, using (5) and (6), we find with CVF from Corollary 1 applied on $f(t, x, y)=y^{\sigma} x$ and the differentials (8) and (9) that the evolution of real wealth is given by, cf. Appendix E, ${ }^{7}$

$$
\begin{aligned}
d a(t)= & {\left[r a(t)+w_{L}^{r}(t)-c^{r}(t)\right] d t-\left[1-\left(1+\gamma_{A}\right)^{-\sigma}\right] a\left(t_{-}\right) d q_{A}(t) } \\
& +\left[\left(\gamma_{B}+1\right)^{\sigma}-1\right] a\left(t_{-}\right) d q_{B}(t)
\end{aligned}
$$

where $r \equiv \sigma\left(\psi_{B}-\psi_{A}\right)+\frac{w_{K}(t)}{p_{I}(t)}$ stands for the real interest rate, $w_{L}^{r}(t) \equiv \frac{w_{L}(t)}{p_{Y}(t)}$ for real labor income, and $c^{r}(t) \equiv \frac{p_{X}(t) c_{X}(t)}{p_{Y}(t)}+c_{Y}(t)$ for real consumption. Again, this budget is very intuitive. Recall that real wealth is the value of the household's capital holdings measured

\footnotetext{
${ }^{7}$ Appendix E-H can be found in the revised discussion paper version Sennewald and Wälde (2006), which is available at www.waelde.com/publications.html.
} 
in units of the consumption good $Y$, i.e., $a=p_{I} k / p_{Y}$. The real interest rate is thus given by $\frac{w_{K}(t)}{p_{I}(t)}$, which is the rate of return of capital, expressed in units of capital, the household receives for her investment in producing $X$ and $Y$, and by $\sigma\left(\psi_{B}-\psi_{A}\right)$, which is the continuous rate of change of the real capital price $p_{I} / p_{Y}$. The latter statement is a consequence of the relation $p_{I} / p_{Y}=\left[p_{X}(t) / p_{Y}(t)\right]^{\sigma}=[B(t) / A(t)]^{\sigma}$ and the dynamics of $A(t)$ and $B(t)$ : As $A(t)$ and $B(t)$ grow continuously at the rates $\psi_{A}$ and $\psi_{B}$, respectively, the relative price $p_{X} / p_{Y}$ changes, also continuously, at the rate $\psi_{B}-\psi_{A}$, which in turn leads to a change of $p_{I} / p_{Y}$ at the rate $\sigma\left(\psi_{B}-\psi_{A}\right)$. A similar story applies to the "jump terms". A jump in one of the TFPs $A(t)$ and $B(t)$ triggers a jump in the real capital price, thus leading to an increase of wealth at the rate $\left[1-\left(1+\gamma_{A}\right)^{-\sigma}\right]$ and $\left[\left(\gamma_{B}+1\right)^{\sigma}-1\right]$, respectively.

\subsection{Application III: The Hamilton-Jacobi-Bellman equation}

In this subsection we show how an appropriate HJB equation can be heuristically derived if one faces a stochastic control problem. For all practical purposes, this only requires the application of CVF.

Take a household trying to find an optimal consumption process $c^{*}(t)$ that maximizes the expected lifetime utility, ${ }^{8}$

$$
E_{t_{0}} \int_{t_{0}}^{\infty} e^{-\rho\left(t-t_{0}\right)} u(c(t)) d t
$$

subject to the budget constraint derived in Subsection 2.2,

$$
d a(t)=[r(t) a(t)+w(t)-p(t) c(t)] d t+\beta a\left(t_{-}\right) d q(t), \quad a\left(t_{0}\right)>0 .
$$

As a starting point, we write the HJB equation in the general form $\mathrm{as}^{9}$

$$
\rho V(t, a(t))=\max _{c(t)}\left\{u(c(t))+\frac{1}{d t} E_{t} d V(t, a(t))\right\},
$$

where the maximum is achieved by the optimal consumption choice $c^{*}(t)$, and $V$ denotes the value function

$$
V(t, a(t)) \equiv E_{t} \int_{t}^{\infty} e^{-\rho(s-t)} u\left(c^{*}(s)\right) d s,
$$

which is the maximized expected lifetime utility in $t$ given wealth $a(t)$. The value function therefore gives the highest value, in units of utility, the household can reach given an amount

\footnotetext{
${ }^{8}$ Later, in the example presented in Section 3, we shall go further into detail about the considered controls.

${ }^{9}$ For a heuristic derivation see Appendix F or Malliaris and Brock (1982) and Turnovsky (2000).
} 
$a(t)$ of wealth. The general HJB equation (13) says that the household chooses consumption in $t$ such that she maximizes her instantaneous return from consumption, which consists of the instantaneous utility flow $u(c(t))$ plus the expected change $\frac{1}{d t} E_{t} d V(t, a(t))$ in the value of wealth corresponding to the consumption choice in $t$. It tells furthermore that the intertemporal return $\rho V(t, a(t))$ from holding $a(t)$ is given by the return from the optimal consumption in $t, u\left(c^{*}(t)\right)+\frac{1}{d t} E_{t} d V(t, a(t))$. We see that, when determining the optimal behavior at $t$, the household only needs to consider the value function at $t$ and its expected change in order to cover future behavior. This is a direct result of Bellman's principle of optimality, see, e.g., Bellman (1957) and cf. also Appendix F.

Assume that $V$ is once continuously differentiable. Obtaining the HJB equation for a specific maximization problem then requires (i) application of CVF on $V(t, a(t)$ ), (ii) computing expectations and (iii) "dividing" by $d t$. With budget constraint (12) CVF from Corollary 3 yields

$$
\begin{aligned}
d V(t, a(t))= & \left\{V_{t}(t, a(t))+V_{a}(t, a(t))\left[r(t) a(t)+w(t)-p(t) c^{*}(t)\right]\right\} d t \\
& +\left[V\left(t,(1+\beta) a\left(t_{-}\right)\right)-V\left(t, a\left(t_{-}\right)\right)\right] d q(t) .
\end{aligned}
$$

Using $E_{t} d q_{t}=\lambda d t$, we get

$$
\begin{aligned}
E_{t} d V(t, a(t))= & \left\{V_{t}(t, a(t))+V_{a}(t, a(t))\left[r(t) a(t)+w(t)-p(t) c^{*}(t)\right]\right\} d t \\
& +\lambda[V(t,(1+\beta) a(t))-V(t, a(t))] d t .
\end{aligned}
$$

Dividing by $d t$ gives finally the HJB equation for the maximization problem consisting of (11) and (12):

$$
\rho V(t, a(t))=\max _{c(t) \geq 0}\left\{\begin{array}{c}
u(c(t))+V_{t}(t, a(t))+V_{a}(t, a(t))\left[r(t) a(t)+w(t)-p(t) c^{*}(t)\right] \\
+\lambda[V(t,(1+\beta) a(t))-V(t, a(t))]
\end{array}\right\} .
$$

This approach is very practical, a rigorous background with the necessary assumptions can be found in Sennewald (2006).

\section{A typical maximization problem}

We now present a maximization problem that consists in determining a household's optimal consumption and investment behavior. Finding closed form expressions for the optimal controls is usually restricted to special cases. Nevertheless, for optimum-consumption problems 
it is usually possible to derive a Keynes-Ramsey rule. We show how this can be achieved, making use of the HJB equation as a necessary criterion for optimality. Then the closed form solution is presented. Its optimality is verified by the fact that the HJB equation together with a certain terminal condition is also a sufficient criterion for optimality.

\subsection{The problem}

Consider a household that is endowed with some initial wealth $a\left(t_{0}\right)>0$. At each instant, the household can invest her wealth $a(t)$ in both a risky and a safe asset. The amount the household holds in the risky asset is denoted by $b(t)$. Her investment in the safe asset is then $a(t)-b(t)$. The price $v_{1}(t)$ of one unit of the risky asset obeys the SDE

$$
d v_{1}(t)=r_{1} v_{1}(t) d t+\beta v_{1}\left(t_{-}\right) d q(t)
$$

where $r_{1} \in \mathbb{R}$ and $\beta>0$. That is, the price of the risky asset grows at each instant with a fixed rate $r_{1}$ and at random points in time it jumps by $\beta$ percent. The randomness comes from the well-known Poisson process $q(t)$ with arrival rate $\lambda$. The price $v_{2}(t)$ of one unit of the safe asset is assumed to follow

$$
d v_{2}(t)=r_{2} v_{2}(t) d t
$$

where $r_{2} \geq 0$. Let the household receive a fixed wage income $w$ and spend $c(t) \geq 0$ on consumption. ${ }^{10}$ Then, in analogy to (3), the household's budget constraint reads ${ }^{11}$

$$
d a(t)=\left\{r_{1} b(t)+r_{2}[a(t)-b(t)]+w-c(t)\right\} d t+\beta b\left(t_{-}\right) d q(t)
$$

Let the household's time preference rate be given by the constant $\rho>0$ and assume that the planning horizon is infinite. Forming expectations about future consumption streams and given the CRRA (constant relative risk aversion) utility function

$$
u(c)=\frac{c^{1-\sigma}-1}{1-\sigma}, \quad \sigma>0, \quad \sigma \neq 1,{ }^{12}
$$

\footnotetext{
${ }^{10}$ Unlike in Subsections 2.2 and 2.4, we consider here real variables expressed in units of the consumption good.

${ }^{11}$ An alternative approach to derive the budget constraint is to start with the assumption of a "selffinancing portfolio", a concept taken from finance, see Appendix G.

${ }^{12}$ The following also applies to the special case $\sigma \rightarrow 1$, i.e. $u(c)=\log c$.
} 
the household's objective is given by maximizing the expected lifetime utility,

$$
E_{t_{0}} \int_{t_{0}}^{\infty} e^{-\rho\left(t-t_{0}\right)} u(c(t)) d t
$$

subject to the budget constraint (17). The time preference rate $\rho$ is assumed to be sufficiently high so that (19) is finite. In order to avoid a trivial investment problem, we assume

$$
r_{1}<r_{2}<r_{1}+\lambda \beta
$$

The guaranteed return $r_{1}$ of the risky asset is lower than the return $r_{2}$ of the riskless asset, while the expected return $r_{1}+\lambda \beta$ of the risky asset is greater than $r_{2}$. Note that this assumption implies that $\beta>0$ which is consistent with our assumption above.

The control variables of the household are the nonnegative consumption stream $c(t)$ and the amount $b(t)$ invested in the risky asset. There exist various types of controls that may be considered: Feedback controls that depend on the whole history of $a(t)$, Markov controls that depend on current time and wealth, or generalized controls that, roughly speaking, do not depend on "anything" observable. Obviously, the class of Markov controls is contained within the two other classes of controls which means that Markov controls may yield a suboptimal performance. Nevertheless, for the problem at hand, and in other applications where the constraint is Markovian as well, ${ }^{13}$ it is in general sufficient to focus on Markov controls only since one obtains as good a performance with Markov controls as with any other class of controls. But observe that, though being extremely plausible, this result is technically not at all obvious. Many authors address this issue and present corresponding theorems that prove the optimal performance of Markov controls under mild conditions. See, e.g., Sennewald (2006, Theorem 5) or, for a setup with Brownian motion, Øksendal (2000, Theorem 11.2.3).

For now assume that there exist optimal Markov controls, denoted by $c^{*}(t)$ and $b^{*}(t)$, maximizing the expected lifetime utility (19) subject to budget constraint (17). Then we define the value function $V$ by

$$
V\left(a\left(t_{0}\right)\right) \equiv E_{t_{0}} \int_{t_{0}}^{\infty} e^{-\rho\left(t-t_{0}\right)} u\left(c^{*}(t)\right) d t .
$$

\footnotetext{
${ }^{13}$ Roughly speaking, the constraint is Markovian if the change, i.e., the differential, of the controlled process only depends on current variables and if the underlying noise process is Markovian, cf. SDE (17).
} 
Finding the optimal Markov controls and the value function can be achieved by the HJB equation, which, derived as in Subsection 2.4 or taken from Sennewald (2006), reads

$$
\rho V(a)=\max _{c \geq 0, b}\left\{u(c)+\left[r_{1} b+r_{2}(a-b)+w-c\right] V^{\prime}(a)+\lambda[V(\tilde{a})-V(a)]\right\}
$$

where $\tilde{a} \equiv a+\beta b$ denotes the post-jump wealth if at wealth $a$ a jump in the risky asset price occurs. The maximum is attained by the optimal Markov control values $c^{*}$ and $b^{*}$ corresponding to wealth $a$. The HJB equation is under certain conditions both a necessary and sufficient criterion for optimality. In the following subsections we show how either property can be used to tackle the control problem.

\subsection{The Keynes-Ramsey rule}

\subsubsection{Preliminary conditions}

Making use of the fact that according to Sennewald (2006, Theorem 3) the HJB equation is a necessary criterion for optimality, we derive in the following a stochastic form of the Keynes-Ramsey rule. This rule tells us how optimal consumption changes over time. Before turning to the actual derivation in Subsection 3.2.2, we first specify state and control space and show that the conditions required in Sennewald (2006) are satisfied in our example.

Let the state and control space be given as follows. Wealth is allowed to become negative, but the debts shall always be covered by the household's lifetime labor income discounted with the safe interest rate $r_{2}$. That is, $a(t)>-w / r_{2}$ for all $t$. Given this condition, it is only natural to assume that consumption shall not exceed total wealth consisting of current physical wealth plus the present value of future labor income,

$$
0 \leq c(t) \leq a(t)+\frac{w}{r_{2}}
$$

In addition, we do not allow short-selling of the risky asset, whereas, on the other hand, the household can finance risky investment by short-selling the safe asset. ${ }^{14}$ Again, the limit for this kind of borrowing is given by lifetime labor income, i.e., $a(t)-b(t) \geq-w / r_{2}$. Hence,

$$
0 \leq b(t) \leq a(t)+\frac{w}{r_{2}}
$$

\footnotetext{
${ }^{14}$ Consider the safe asset as a bank account and observe that in many countries short-selling of stocks is not allowed.
} 
Then the set of admissible controls contains all cádlág processes $c(t)$ and $b(t)$ satisfying conditions (22) and (23) such that the associated wealth process always remains above the level $-w / r_{2}$. Assume that the optimal Markov controls $c^{*}(t)$ and $b^{*}(t)$ are admissible.

So far, working with the HJB equation as a necessary criterion has required, among other things, the boundedness of utility function (18) and of the coefficients in budget constraint (17). Apparently, neither (17) nor (18) do satisfy this condition. Sennewald (2006, Theorem 3) relaxes this requirement and shows that linear boundedness suffices. That means we can still use the HJB equation if we find constants $\mu, p_{i}, q_{i}>0, i=1,2$, such that for all $a>-w / r_{2}$ and admissible $c$ and $b$

$$
\begin{gathered}
|u(c)| \leq \mu(c+1), \\
\left|r_{1} b+r_{2}(a-b)+w-c\right| \leq p_{1}|a|+q_{1},
\end{gathered}
$$

and

$$
|\beta b| \leq p_{2}|a|+q_{2}
$$

In addition, the optimal controls $c^{*}$ and $b^{*}$ must be linearly bounded in $a$ too. That is, for some $\gamma>0$,

$$
\left\|\left(c^{*}, b^{*}\right)\right\| \equiv \sqrt{c^{* 2}+b^{* 2}} \leq \gamma(1+a) .
$$

Using (22) and (23), we easily obtain (25) to (27) with $p_{1}=\max \left\{r_{2}, 1-r_{1}\right\}, q_{1}=$ $\max \left\{w,\left(1-r_{1}\right) w / r_{2}\right\}, p_{2}=\beta, q_{2}=\beta w / r_{2}$, and $\gamma=\sqrt{2} w / r_{2} \cdot{ }^{15}$ Condition (24) is trivially met with $\mu=\frac{1}{1-\sigma}$ if the risk aversion parameter $\sigma$ in utility function (18) is less than one. In the case of log-utility or for $\sigma>1$, things are more complicated. Though bounded from above, ${ }^{16} u(c)$ is not linearly bounded from below since it falls too fast toward $-\infty$ as $c$ tends to 0 . We therefore assume that there exists a threshold $\varepsilon>0$ below which the consumption expenditure never falls. This assumption is justified if one recalls that marginal utility becomes infinity as consumption tends to 0 . Thus, zero-consumption can never be optimal. Hence, if we choose $\varepsilon$ small enough, we find that utility is bounded from below by $\ln \varepsilon$ and $\left(\varepsilon^{-(\sigma-1)}-1\right) /(1-\sigma)$, respectively. Jointly with the (linear) boundedness from above, this immediately yields $(24)$ with $\mu=|\ln \epsilon|$ for $\sigma=1$ and $\mu=\left(\varepsilon^{-(\sigma-1)}-1\right) /(\sigma-1)$ for $\sigma>1$.

\footnotetext{
${ }^{15}$ Note that if we had choosen as control variable the share of wealth invested in the risky asset instead of the absolut amount $b$, condition (27) could hardly be satisfied.

${ }^{16} \ln c$ is linearly bounded from above by $c$, whereas an upper bound for $\frac{c^{1-\sigma}-1}{1-\sigma}, \sigma>1$, is given by $\frac{1}{\sigma-1}$.
} 
Beside the linear-boundedness conditions (24)-(27), a certain regularity condition must hold, see assumption (H4) in Sennewald (2006). But in order to satisfy this technical condition, we merely need to assume a sufficiently high time preference rate, namely $\rho>q_{1}+\lambda q_{2}$, cf. Remark 1(iii) in Sennewald (2006). ${ }^{17}$ Then, given that the value function is sufficiently smooth, the HJB equation is a necessary criterion for optimality.

\subsubsection{Deriving the Keynes-Ramsey rule}

Since $c^{*}$ and $b^{*}$ maximize the right-hand side in the HJB equation (21), the following firstorder conditions must be satisfied if $c^{*}$ and $b^{*}$ are not corner solutions with respect to the constraints (22) and (23):

$$
u^{\prime}\left(c^{*}\right)=V^{\prime}(a)
$$

and

$$
V^{\prime}(a)\left(r_{1}-r_{2}\right)+\lambda V^{\prime}\left(\tilde{a}^{*}\right) \beta=0,
$$

where $\tilde{a}^{*} \equiv a+b^{*} \beta$ denotes the post-jump wealth for the optimal investment behavior. Replacing according to (28) $V^{\prime}$ by $u^{\prime}$ in equation (29) yields

$$
\frac{u^{\prime}\left(\tilde{c}^{*}\right)}{u^{\prime}\left(c^{*}\right)}=\frac{r_{2}-r_{1}}{\lambda \beta}
$$

where $\tilde{c}^{*}$ denotes the optimal consumption choice corresponding to $\tilde{a}^{*}$. Hence, the ratio for optimal consumption after and before a jump is constant:

$$
\frac{\tilde{c}^{*}}{c^{*}}=\left(\frac{\lambda \beta}{r_{2}-r_{1}}\right)^{1 / \sigma} \text {. }
$$

Since by assumption (20) the term on the right-hand side is greater than one, this equation shows that consumption jumps upwards if a jump in the risky asset price occurs. This result is not surprising since, if the risky asset price jumps upwards, so does the household's wealth.

In the next step, we compute the evolution of $V^{\prime}\left(a^{*}(t)\right)$, where $a^{*}(t)$ denotes the wealth process associated to the optimal consumption and investment behavior. Assume that $V$ is twice continuously differentiable. Then, due to budget constraint (17), CVF from Corollary 3 yields

$$
\begin{aligned}
d V^{\prime}\left(a^{*}(t)\right)= & \left\{r_{1} b^{*}(t)+r_{2}\left[a^{*}(t)-b^{*}(t)\right]+w-c^{*}(t)\right\} V^{\prime \prime}\left(a^{*}(t)\right) d t \\
& +\left[V^{\prime}\left(\tilde{a}^{*}\left(t_{-}\right)\right)-V^{\prime}\left(a^{*}\left(t_{-}\right)\right)\right] d q(t) .
\end{aligned}
$$

\footnotetext{
${ }^{17}$ In any cases, $\rho$ has to be high enough in order to ensure a finite objective function (19). The regularity condition (H4), however, might require an even higher $\rho$.
} 
On the other hand, differentiating the maximized HJB equation (21) evaluated at $a^{*}(t)$ yields under application of the envelope theorem

$$
\begin{aligned}
\rho V^{\prime}\left(a^{*}(t)\right)= & \left\{r_{1} b^{*}(t)+r_{2}\left[a^{*}(t)-b^{*}(t)\right]+w-c^{*}(t)\right\} V^{\prime \prime}\left(a^{*}(t)\right)+r_{2} V^{\prime}\left(a^{*}(t)\right) \\
& +\lambda\left[V^{\prime}\left(\tilde{a}^{*}(t)\right)-V^{\prime}\left(a^{*}(t)\right)\right] .
\end{aligned}
$$

Rearranging gives

$$
\begin{aligned}
\left\{r_{1} b^{*}(t)+r_{2}\right. & {\left.\left[a^{*}(t)-b^{*}(t)\right]+w-c^{*}(t)\right\} V^{\prime \prime}\left(a^{*}(t)\right) } \\
& =\rho V^{\prime}\left(a^{*}(t)\right)-r_{2} V^{\prime}\left(a^{*}(t)\right)-\lambda\left[V^{\prime}\left(\tilde{a}^{*}(t)\right)-V^{\prime}\left(a^{*}(t)\right)\right] .
\end{aligned}
$$

Inserting this expression into (32) yields

$$
\begin{aligned}
d V^{\prime}\left(a^{*}(t)\right)= & \left\{\left(\rho-r_{2}\right) V^{\prime}\left(a^{*}(t)\right)-\lambda\left[V^{\prime}\left(\tilde{a}^{*}(t)\right)-V^{\prime}\left(a^{*}(t)\right)\right]\right\} d t \\
& +\left[V^{\prime}\left(\tilde{a}^{*}\left(t_{-}\right)\right)-V^{\prime}\left(a^{*}\left(t_{-}\right)\right)\right] d q(t) .
\end{aligned}
$$

Replacing, according to the first-order condition (28) for optimal consumption, $V^{\prime}$ by $u^{\prime}$ we obtain

$$
\begin{aligned}
d u^{\prime}\left(c^{*}(t)\right)= & \left\{\left(\rho-r_{2}\right) u^{\prime}\left(c^{*}(t)\right)-\lambda\left[u^{\prime}\left(\tilde{c}^{*}(t)\right)-u^{\prime}\left(c^{*}(t)\right)\right]\right\} d t \\
& +\left[u^{\prime}\left(\tilde{c}^{*}\left(t_{-}\right)\right)-u^{\prime}\left(c^{*}\left(t_{-}\right)\right)\right] d q(t) .
\end{aligned}
$$

Applying now the CVF from Corollary 3 to $f(x)=\left(u^{\prime}\right)^{-1}(x)$ leads to the Keynes-Ramsey rule for general utility functions $u$,

$$
-\frac{u^{\prime \prime}\left(c^{*}\right)}{u^{\prime}\left(c^{*}(t)\right)} d c^{*}(t)=\left\{r_{2}-\rho-\lambda\left[1-\frac{u^{\prime}\left(\tilde{c}^{*}(t)\right)}{u^{\prime}\left(c^{*}(t)\right)}\right]\right\} d t-\left[\tilde{c}^{*}\left(t_{-}\right)-c^{*}\left(t_{-}\right)\right] \frac{u^{\prime \prime}\left(c^{*}\right)}{u^{\prime}\left(c^{*}(t)\right)} d q(t) .
$$

For the CRRA utility function as given as in (18) we get by eliminating $u^{\prime}\left(\tilde{c}_{t}^{*}\right)$ according to (30) and $\tilde{c}_{t}^{*}$ according to $(31)$

$$
\frac{d c^{*}(t)}{c^{*}\left(t_{-}\right)}=\frac{1}{\sigma}\left[r_{2}-\lambda\left(1-\frac{r_{2}-r_{1}}{\lambda \beta}\right)-\rho\right] d t+\left[\left(\frac{\lambda \beta}{r_{2}-r_{1}}\right)^{1 / \sigma}-1\right] d q(t) .
$$

The optimal change in consumption can thus be expressed in terms of well-known parameters. As long as the price of the risky asset does not jump, optimal consumption grows constantly by the rate $\left[r_{2}-\lambda\left(1-\frac{r_{2}-r_{1}}{\lambda \beta}\right)-\rho\right] / \sigma$. The higher the risk-free interest rate $r_{2}$ and the lower the guaranteed interest rate $r_{1}$ of the risky asset, the discrete growth rate $\beta$, the 
probability of a price jump $\lambda$, the time preference rate $\rho$, and the risk aversion parameter $\sigma$, the higher becomes the consumption growth rate. When the risky asset price jumps, consumption jumps as well to its new higher level $c^{*}(t)=\left(\frac{\lambda \beta}{r_{2}-r_{1}}\right)^{1 / \sigma} c^{*}\left(t_{-}\right)$. Here the growth rate depends positively on $\lambda, \beta$, and $r_{1}$, whereas $r_{2}$ and $\sigma$ have negative influence. A detailed discussion about the impact of risk on the average consumption growth is provided in Subsection 3.4.2.

\subsection{A closed form solution}

\subsubsection{General approach: Guessing the value function}

A Keynes-Ramsey rule describes "only" the optimal change in consumption over time. In the following we present a closed form solution, which tells us explicitly how to choose optimal consumption and investment levels. Obtaining closed form expressions for the optimal controls and the value function is not obvious. ${ }^{18}$ Looking for them has a long tradition in finance (see, e.g., Merton, 1969, 1971 or Framstad et al., 2001) and also in macroeconomics (see, e.g., Wälde 1999a). Finding a closed form solution is in general the result of an "educated guess". That means, we consider already solved optimization problems that are similar to ours and try to deduce a solution from them. Chang (2004) devotes an entire chapter on how to derive value functions in various setups with Brownian motion. After having found a candidate for a solution, it has to be verified. To this end, one can use a so called verification theorem. Such a theorem tells us that, if the candidate for the optimal solution solves the HJB equation and if furthermore certain limiting conditions are satisfied, the candidate is indeed optimal, cf. Sennewald (2006, Theorem 4). In other words, the HJB equation is a sufficient criterion for optimality. Interestingly, unlike necessity this sufficiency property does not require any boundedness conditions on the primitives at all.

From similar consumption and investment problems in Merton $(1969,1971)$ and elsewhere

\footnotetext{
${ }^{18}$ Unfortunately, finding explicit expressions for the optimal controls is rather the exception. In more general setups, for example, with non-constant interest rates (which are typical when modeling transitional dynamics or when considering macroeconomic models of growth for non $A K$-type economies) closed-form solutions can only be derived if certain parameter restriction are met, see, e.g., Wälde (2005) and the references therein. The same holds if labor income is stochastic or if the capital market is imperfect, see, e.g., van der Ploeg (1993) (for a discrete-time setup) or Duffie, Fleming, Soner, and Zariphopoulou (1997). Deriving a Keynes-Ramsey rule along the lines of Subsection 3.2 should, however, always be possible.
} 
we can guess that the value function is of the form

$$
J(a)=\frac{\Gamma_{1}\left[a+\Gamma_{2}\right]^{1-\sigma}-\Gamma_{3}}{1-\sigma}
$$

with unknown constants $\Gamma_{1}, \Gamma_{2}$, and $\Gamma_{3}$. In the following steps, this rather vague expression for the candidate of the value function is used to derive the optimal consumption and investment behavior as well as explicit expression for $\Gamma_{1}, \Gamma_{2}$ and $\Gamma_{3}$.

\subsubsection{Deriving and verifying optimal consumption and investment}

Let the state space again be given by all $a>-w / r_{2}$, while for the moment the control space constraints $(22)$ and $(23)$ are relaxed to $c \geq 0$ and $b \in \mathbb{R}$. Starting from the candidate for the value function in (34) and using the verification theorem 4 in Sennewald (2006), we show how the optimal consumption and investment behavior can be both derived and verified at the same time. The proceeding consists of two steps:

1.) Does the candidate for the value function solve the HJB equation

$$
\rho J(a)=\max _{\{c \geq 0, b \in \mathbb{R}\}}\left\{u(c)+\left[r_{1} b+r_{2}(a-b)+w-c\right] J^{\prime}(a)+\lambda[J(\tilde{a})-J(a)]\right\}
$$

and is the maximum in (35) attained by the candidates for the optimal controls, $c^{*}$ and $b^{*}$ ?

2.) Are the limiting conditions

$$
\lim _{t \rightarrow \infty} E_{t_{0}}\left[e^{-\rho t} J\left(a^{*}(t)\right)\right]=0
$$

and

$$
\lim _{t \rightarrow \infty} E_{t_{0}}\left[e^{-\rho t} J(a(t))\right] \geq 0
$$

satisfied, where $a(t)$ denotes the wealth process associated to an arbitrary admissible Markov control?

At first, we derive in step 1.) the constants $\Gamma_{1}, \Gamma_{2}, \Gamma_{3}$ and the candidates for the optimal controls such that HJB equation (35) holds. Then we show in step 2.) that these candidates satisfy limiting conditions (36) and (37).

Step 1.) (Cf. also Sennewald, 2006, Corollary 4) Since the right-hand side of the HJB equation (35) is strictly concave in $c$ and $b$, the HJB equation holds if the following two points are satisfied: (a) The candidates for the optimal controls solve the first-order conditions for the maximum on the right-hand side in (35); (b) The candidates for the optimal controls yield equality in (35). 
Point (a) makes sure that $c^{*}$ and $b^{*}$ maximize the right-hand side in (35). If in addition point (b) is satisfied, we can conclude that the HJB equation holds.

ad a) The first-order conditions read (cf. also (28) and (29)) $u^{\prime}\left(c^{*}\right)=J^{\prime}(a)$ and $J^{\prime}(a)\left(r_{1}-r_{2}\right)+\lambda J^{\prime}\left(\tilde{a}^{*}\right) \beta=0$. Rearranging the latter equation yields $\left(a+\Gamma_{2}\right)^{-\sigma}\left(r_{2}-r_{1}\right)=$ $\lambda\left(a+\beta b^{*}+\Gamma_{2}\right)^{-\sigma} \beta$. Therefore, the optimal consumption must be

$$
c^{*}=\Gamma_{1}^{-\frac{1}{\sigma}}\left(a+\Gamma_{2}\right),
$$

and the optimal share invested in the risky asset is

$$
b^{*}=\frac{1}{\beta}\left[\left(\frac{\lambda \beta}{r_{2}-r_{1}}\right)^{\frac{1}{\sigma}}-1\right]\left(a+\Gamma_{2}\right) .
$$

ad b) Inserting (38) and (39) into the maximized HJB equation (35) gives unique expressions for $\Gamma_{1}, \Gamma_{2}$, and $\Gamma_{3}$, such that finally the candidate for the value function reads ${ }^{19,20}$

$$
J(a)=\frac{\frac{1}{\psi^{\sigma}}\left(a+\frac{w}{r_{2}}\right)^{1-\sigma}-\frac{1}{\rho}}{1-\sigma},
$$

with the constant

$$
\psi=\frac{1}{\sigma}(\rho+\lambda)-\frac{1-\sigma}{\sigma}\left(r_{2}+\frac{r_{2}-r_{1}}{\beta}\right)-\lambda\left(\frac{\lambda \beta}{r_{2}-r_{1}}\right)^{\frac{1-\sigma}{\sigma}} .
$$

Thus, according to (38), optimal consumption must obey

$$
c^{*}=\psi\left(a+\frac{w}{r_{2}}\right)
$$

whereas, by (39), the optimal amount held in the risky asset can only be

$$
b^{*}=\frac{1}{\beta}\left[\left(\frac{\lambda \beta}{r_{2}-r_{1}}\right)^{\frac{1}{\sigma}}-1\right]\left(a+\frac{w}{r_{2}}\right) .
$$

Note that total wealth $a+w / r_{2}$ is according to state space constraint $a>-w / r_{2}$ always positive. Thus, in order to derive economically meaningful solutions, we require $\psi$ to be positive too. That means the time preference rate must be high enough, namely, after rearranging (41), such that

$$
\rho>(1-\sigma) r_{2}+\frac{r_{2}-r_{1}}{\beta}\left\{\sigma\left[\left(\frac{\lambda \beta}{r_{2}-r_{1}}\right)^{\frac{1}{\sigma}}-1\right]-\left[\frac{\lambda \beta}{r_{2}-r_{1}}-1\right]\right\} .
$$

\footnotetext{
${ }^{19}$ More precisely, $\Gamma_{1}, \Gamma_{2}$, and $\Gamma_{3}$ follow by a comparison of coefficients, see Appendix $H$ or, for a setup with Brownian motion, Chang (2004, Ch. 5).

${ }^{20}$ In case of $\log$-utility we obtain $\psi=\rho$ and $V(a)=\frac{1}{\rho}\left[\ln \left(a+\frac{w}{r_{2}}\right)+\ln \rho-1+\frac{\lambda\left(\frac{r_{2}-r_{1}}{\lambda \beta}-1+\ln \frac{\lambda \beta}{r_{2}-r_{1}}\right)+r_{2}}{\rho}\right]$.
} 
Using Lemma 2 in Appendix B, we find that the right-hand side is negative iff $\sigma>1$, zero iff $\sigma=0$, and positive iff $\sigma<1$. Thus, if $\sigma \geq 1$, (44) is trivially satisfied for any $\rho>0$.

Notice that with (42) and (43), we have derived the (only) controls corresponding to the guessed value function (34) that maximize the HJB equation. Thus, if now the terminal conditions in step 2.) are satisfied, we know that these controls are optimal.

Step 2.) This step requires some calculation. At first, we check limiting condition (36). Due to the shape of $J$ as given as in (40), it suffices to show that

$$
\lim _{t \rightarrow \infty} e^{-\rho t} E_{t_{0}}\left[a^{*}(t)+\frac{w}{r_{2}}\right]^{1-\sigma}=0
$$

To this end, we derive an explicit expression for $\left[a^{*}(t)+w / r_{2}\right]^{1-\sigma}$. According to CVF in Corollary 3 , the total wealth process $a^{*}(t)+w / r_{2}$ obeys budget constraint (17) with starting point $a\left(t_{0}\right)+w / r_{2}$. Inserting the candidates for optimal consumption and investment from (42) and (43) into the budget constraint yields

$$
d\left[a^{*}(t)+\frac{w}{r_{2}}\right]=\eta_{1}\left[a^{*}(t)+\frac{w}{r_{2}}\right] d t+\eta_{2}\left[a^{*}\left(t_{-}\right)+\frac{w}{r_{2}}\right] d q(t),
$$

where $\eta_{1}=\frac{1}{\sigma}\left[r_{2}-\lambda\left(1-\frac{r_{2}-r_{1}}{\lambda \beta}\right)-\rho\right]$ and $\eta_{2}=\left(\frac{\lambda \beta}{r_{2}-r_{1}}\right)^{\frac{1}{\sigma}}-1$. The solution of this linear stochastic differential equation reads (see Garcia and Griego, 1994)

$$
a^{*}(t)+\frac{w}{r_{2}}=\left[a\left(t_{0}\right)+\frac{w}{r_{2}}\right] \exp ^{\eta_{1}\left(t-t_{0}\right)+\ln \left(1+\eta_{2}\right) q(t)} .
$$

Using that for any Poisson distributed random variable $X$ with parameter $\lambda, E \exp ^{a X+b}=$ $\exp ^{\lambda\left(\exp ^{b}-1\right)+a}$, we find further

$$
E_{t_{0}}\left[a^{*}(t)+\frac{w}{r_{2}}\right]^{1-\sigma}=\left[a\left(t_{0}\right)+\frac{w}{r_{2}}\right]^{1-\sigma} \exp \left\{(1-\sigma) \eta_{1}+\lambda\left[\left(1+\eta_{2}\right)^{1-\sigma}-1\right]\right\}\left(t-t_{0}\right) .
$$

Therefore, (45) and thus (36) as well are satisfied if and only if

$$
\rho>(1-\sigma) \eta_{1}+\lambda\left[\left(1+\eta_{2}\right)^{1-\sigma}-1\right]
$$

Inserting $\eta_{1}$ and $\eta_{2}$ and rearranging shows that this parameter constellation is already met by (44). The limiting condition (36) is hence satisfied. This connection between positive consumption and limiting condition (36) was also found by Merton (1990) in a revised version of his paper from 1969 for the case with Brownian motion as noise. 
It remains to be shown that limiting inequality (37) holds for any arbitrary admissible Markov control. For the case $0<\sigma<1$, we use that the candidate for the value function (40) is always greater than $-[\rho(1-\sigma)]^{-1}$. Therefore, $\lim _{t \rightarrow \infty} E_{t_{0}}\left[e^{-\rho t} J(a(t))\right] \geq$ $-\lim _{t \rightarrow \infty} \frac{e^{-\rho t}}{\rho(1-\sigma)}=0$ is trivially satisfied.

For $\sigma \geq 1$, finding a lower bound for $J(a(t))$ is less simple since we can not rule out that $J(a(t))$ approaches $-\infty$, which happens if $a(t)$ approaches the boundary of the state space, $-w / r_{2}$. Thus, for (37) to be satisfied, we have to show that $J(a(t))$ tends to $-\infty$ with a rate less than $\rho$. To this end, we first derive the lowest $a(t)$ the household can achieve. Assume without loss of generality that the household is in debt, $a(t)<0$. Now, introducing again control space constraints (22) and (23), one can show easily that the infinitesimal change of $a(t)$ is always greater than $-\left(1-r_{1}\right)\left[a(t)+w / r_{2}\right]$. Thus, using a comparison principle as, e.g., Bassan et al. (1993, Corollary 3.5), we conclude that $a(t) \geq \tilde{a}(t)$, where $\tilde{a}(t)$ is the solution of $d \tilde{a}(t)=-\left(1-r_{1}\right)\left[\tilde{a}(t)+w / r_{2}\right] d t, \tilde{a}\left(t_{0}\right)=a\left(t_{0}\right)$. Solving this linear differential equation yields $\tilde{a}(t)=\left(1-w / r_{2}\right) \exp ^{-\left(1-r_{1}\right)\left[t-t_{0}\right]} a\left(t_{0}\right)-w / r_{2}$. Hence,

$$
\begin{aligned}
\lim _{t \rightarrow \infty} E_{t_{0}}\left[e^{-\rho t} J(a(t))\right] & \geq \lim _{t \rightarrow \infty} e^{-\rho t} J(\tilde{a}(t)) \\
& =-\frac{\left[\left(1-\frac{w}{r_{2}}\right) a\left(t_{0}\right)\right]^{-(\sigma-1)} \exp ^{-\rho t_{0}}}{(\sigma-1) \psi^{\sigma}} \lim _{t \rightarrow \infty} \exp ^{-\left[\rho-(\sigma-1)\left(1-r_{1}\right)\right]\left[t-t_{0}\right]}
\end{aligned}
$$

Thus, for limiting condition (37) to be satisfied, we need again a sufficiently high time preference, namely $\rho>(\sigma-1)\left(1-r_{1}\right)$. The latter condition completes the verification, and the derived candidates (42) and (43) for the optimal controls are indeed optimal.

Summarizing, verification only required the time preference rate to be high enough. For the case $\sigma \geq 1$ we introduced again control space constraints (22) and (23). It remains to be shown that for $\sigma \geq 1$ the optimal controls indeed satisfy these constraints. Inserting the expression (42) and (43) for optimal consumption and investment into (22) and (23), respectively, shows that for this purpose we need merely to assume that $\psi \leq 1$ and that $\lambda \beta /\left(r_{2}-r_{1}\right) \leq(1+\beta)^{\sigma}$. The first condition is only natural since otherwise consumption was permanently higher than total wealth. The latter inequality means that the expected return $\lambda \beta$ from a jump in the risky asset price shall not exceed the "opportunity costs" $r_{2}-r_{1}$ for investment in the risky asset too much. Then, the household is not willing to borrow more than her total wealth $a+w / r_{2}$ to finance risky investment.

Finally, there is still one interesting point that shall be addressed, namely the uniqueness 
of the derived solution $c^{*}, b^{*}$, and $J$. First, since we know by the preceding verification that $J$ in (40) is equal to the value function $V$, uniqueness of $J$ follows directly from the uniqueness of $V$, which is due to its definition on page 14. Then we use that the value function and any set of optimal Markov controls satisfy according to Subsection 3.2 necessarily the HJB equation. Thus, optimal controls are associated to $J$ by the first-order conditions (28) and (29) for maximizing the HJB equation. Now, since $u^{\prime}$ and $J^{\prime}$ in (28) and (29) are monotone (and unique), these first-order conditions pin-down uniquely the optimal controls $c^{*}$ and $b^{*}$ as presented in (42) and (43).

\subsection{Economic insights}

\subsubsection{General results}

Both optimal consumption (42) and optimal investment (43) are constant fractions of total wealth, $a+w / r_{2}$. The household thus does not relate optimal consumption and investment only to current physical wealth but also to lifetime labor income. This result is in line with the findings derived by e.g., Merton (1971) for Brownian motion as noise.

What has not been stressed before is that this implies a behavior that seems somehow paradox in light of the household's (constant relative) risk aversion: First, if the household is poor or in debt ( $a$ very low or negative), consumption exceeds physical wealth and the household runs (further) into debt. Second, dividing (43) by a shows that the lower physical wealth, the higher the share $b^{*} / a$ of physical wealth invested in the risky asset. In addition, when being very poor or being in debt, the optimally behaving household "borrows" (even more) by short-selling the risk-free asset in order to finance risky investment $\left(a-b^{*}<0\right)$. However, in either case, the households can act in that way as he knows that future wage income is used to repay the debt.

\subsubsection{Risk and consumption growth}

In the following we consider the impact of uncertainty on average consumption growth. Uncertainty is measured by the variance of the stochastic component, which is the price $v_{1}(t)$ of the risky asset given by SDE (15). We must thus change parameters in such a way that the variance of $v_{1}(t)$ rises while its expectation remains unaltered. In other words, we consider a mean preserving spread. 
Following Appendix A, expectation of $v_{1}(t)$ is given by

$$
E_{0} v_{1}(t)=v_{1}\left(t_{0}\right) \exp ^{\left(r_{1}+\lambda \beta\right)\left(t-t_{0}\right)}
$$

and variance by $\operatorname{Var}_{0} v_{1}(t)=\left[E_{0} v_{1}(t)\right]^{2}\left[\exp ^{\lambda \beta^{2}\left(t-t_{0}\right)}-1\right]$. A mean preserving spread can thus be achieved by an increase of the randomly occurring price jump $\beta$ to $\kappa \beta$, where $\kappa>1$, and by a simultaneous decrease of the frequency of such a price jump, i.e., by reducing the arrival rate $\lambda$ to $\lambda / \kappa{ }^{21}$ Then the expectation of the new price process, which shall be denoted by $v_{1}^{\kappa}(t)$, is identical to $(46)$, while the variance increases to

$$
\operatorname{Var}_{0} v_{1}^{\kappa}(t)=\left[E_{0} v_{1}(t)\right]^{2}\left[\exp ^{\kappa \lambda \beta^{2}\left(t-t_{0}\right)}-1\right]>\operatorname{Var}_{0} v_{1}(t), \quad \kappa>1
$$

The household's response to higher risk, captured by $\kappa>1$, is a reallocation of his portfolio toward the risk-free asset (a result easily derived by considering $b^{*}$ in (43)) and, as shown in Appendix B, an increase (decrease) of his consumption level in case of low risk aversion, i.e., $\sigma<1$ (high risk aversion, i.e., $\sigma>1$ ), whereas for $\sigma=1$ consumption expenditure remains unchanged at $c^{*}=\rho\left(a+w / r_{2}\right)$. Thus, only in case of high risk aversion $(\sigma>1)$ the household has a motive for precautionary saving. The result on $b^{*}$ does not require further explanation in light of the household's risk aversion. Neither does the consumption shift since the mechanism behind it, though for different settings, is well-known and extensively discussed by many authors. Take, for example Merton (1969), who analyses uncertainty from Brownian motion, or Sandmo (1970), who considers an one-asset consumption problem in discrete time. They show that in case of low risk aversion $(\sigma<1)$ the intertemporal substitution effect dominates the income effect, while the contrary holds true for $\sigma>1$. If $\sigma=1$, both effects offset each other.

As the latter statements show, the total effect of risk on the average consumption growth is not obvious, at least not for the empirical relevant case $\sigma>1$. In order to find out whether consumption growth accelerates or slows down, we consider Keynes-Ramsey rule (33) applied on the optimal consumption process $c_{\kappa}^{*}(t)$ that is associated to risk parameter $\kappa$. Forming expectation yields the average growth rate of $c_{\kappa}^{*}(t)$,

$$
\eta(\kappa) \equiv \frac{d E_{0} c_{\kappa}^{*}(t) / d t}{E_{0} c_{\kappa}^{*}(t)}=\frac{1}{\sigma}\left[r_{2}-\frac{\lambda}{\kappa}\left(1-\frac{r_{2}-r_{1}}{\lambda \beta}\right)-\rho\right]+\frac{\lambda}{\kappa}\left[\left(\frac{\lambda \beta}{r_{2}-r_{1}}\right)^{\frac{1}{\sigma}}-1\right] .
$$

\footnotetext{
${ }^{21}$ This is an alternative to Steger (2005) who uses two symmetric Poisson processes instead of one here.
} He obtains higher risk at an invariant mean by increasing the symmetric jump size. 
The change of consumption growth $\eta^{\prime}$ in response to increasing risk is then simply derived by differentiating the latter expression with respect to $\kappa$, which yields evaluated at $\kappa=1$

$$
\eta^{\prime} \equiv \eta^{\prime}(1)=\frac{\lambda}{\sigma}\left(1-\frac{r_{2}-r_{1}}{\lambda \beta}\right)-\lambda\left[\left(\frac{\lambda \beta}{r_{2}-r_{1}}\right)^{\frac{1}{\sigma}}-1\right] \text {. }
$$

Appendix $\mathrm{C}$ shows that $\eta^{\prime}<0$. Hence, increasing risk leads to lower expected consumption growth for any level of risk aversion. In particular, in case of log-utility, the average consumption growth is lower under uncertainty than in the corresponding deterministic setting, despite the identical consumption rule $c^{*}=\rho\left(a+w / r_{2}\right)$.

\subsubsection{Precautionary saving and reallocation}

We now distinguish between two channels through which uncertainty influences growth, the precautionary saving effect $\eta_{\text {prec }}^{\prime}$ and the portfolio-reallocation effect $\eta_{\text {reallo }}^{\prime}$. It turns out that the impact of the precautionary saving effect is ambiguous, depending on the household's risk aversion, while reallocation always implies lower average consumption growth. More precisely, we find that in case of low risk aversion $(\sigma<1)$, the precautionary saving effect is negative and amplified by the reallocation effect, whereas if risk aversion is high $(\sigma>1)$, the precautionary saving effect is positive and dominated by the reallocation effect. In case of log-utility $(\sigma=1)$ the decrease in the expected consumption growth is entirely due to portfolio reallocation.

We can identify the precautionary saving effect by considering expected growth of the optimal consumption process $c_{\kappa, \text { prec }}^{*}(t)$ that is obtained upon eliminating the reallocation effect. That means, $c_{\kappa, \text { prec }}^{*}(t)$ is the solution of an optimum-consumption problem in which the household cannot reallocate her portfolio or, in other words, in which for all $\kappa>1$ the amount held in the risky asset is given by $b^{*}$ from (43). The corresponding Keynes-Ramsey rule is derived in Appendix D, equation (56). Forming expectation yields the expected "precautionary consumption growth"

$$
\eta_{\text {prec }}(\kappa) \equiv \frac{d E_{0} c_{\kappa, \text { prec }}^{*}(t) / d t}{E_{0} c_{\kappa, \text { prec }}^{*}(t)}=-\frac{1}{\sigma}\left\{(\rho-r)-\frac{\lambda}{\kappa}\left[(1+\kappa \beta \gamma)^{1-\sigma}-1\right]\right\}+\lambda \beta \gamma,
$$

where $\gamma \equiv \frac{1}{\beta}\left[\left(\frac{\lambda \beta}{r_{2}-r_{1}}\right)^{\frac{1}{\sigma}}-1\right]$. Differentiating with respect to $\kappa$, replacing $\gamma$, and evaluating the derived expression at $\kappa=1$ leads to the precautionary saving effect,

$$
\eta_{\text {prec }}^{\prime} \equiv \eta_{\text {prec }}^{\prime}(1)=\frac{\lambda}{\sigma}\left(1-\frac{r_{2}-r_{1}}{\lambda \beta}\right)-\lambda\left[\left(\frac{\lambda \beta}{r_{2}-r_{1}}\right)^{\frac{1}{\sigma}}-1\right] \frac{r_{2}-r_{1}}{\lambda \beta} .
$$


Rearranging shows that $\eta_{\text {prec }}^{\prime}<0$ iff $\sigma\left[\left(\frac{\lambda \beta}{r_{2}-r_{1}}\right)^{\frac{1}{\sigma}}-1\right]>\frac{\lambda \beta}{r_{2}-r_{1}}-1$, which in turn holds true iff $\sigma<1$, see Lemma 2 in Appendix B. Analogously we obtain for $\sigma>1, \eta_{\text {prec }}^{\prime}>0$ and for $\sigma=1, \eta_{\text {prec }}^{\prime}=0$. Thus, if risk aversion is low (high), increasing risk leads to lower (higher) consumption growth induced by precautionary saving, whereas, if $\sigma=1$, it has no impact on the consumption growth that is due to precautionary saving at all. These findings mirror the aforementioned result on the impact of uncertainty on the optimal consumption rule.

The reallocation effect $\eta_{\text {reallo }}^{\prime}$ is now obtained by the difference $\eta^{\prime}-\eta_{\text {prec }}^{\prime}$, which reads with (48) and (50)

$$
\eta_{\text {reallo }}^{\prime}=\lambda\left[\left(\frac{\lambda \beta}{r_{2}-r_{1}}\right)^{\frac{1}{\sigma}}-1\right]\left(\frac{r_{2}-r_{1}}{\lambda \beta}-1\right) .
$$

According to assumption (20), this expression is always negative which means that reallocation due to increasing uncertainty lowers average consumption growth. This result is not surprising in view of the aforementioned reallocation toward the risk-free asset since as a consequence the average return of wealth declines.

\section{Conclusion}

This paper has given examples of how the CVF and the HJB equation can be used to analyze optimal behavior in an optimal control setup of Poisson uncertainty. When a closed form solution for optimal behavior is available, further analysis is straightforward. When only a Keynes-Ramsey rule can be derived, further analysis can use, e.g., phase diagrams to understand properties of optimal behavior.

The presented derivations and results should apply in different setups with Poisson processes as well. The principles of deriving a Keynes-Ramsey rule or closed form solutions, when available, remain the same.

We assumed throughout the paper independency of the underlying Poisson processes. A more realistic modeling, however, might require correlated processes. A derivation of CVF and HJB equation for such setups is left for further research.

\section{Appendix}

The appendix is available at www.waelde.com/publications.html 


\section{References}

Aase, K. K. (1984): "Optimum Portfolio Diversification in a General Continuous-Time Model," Stochastic Processes and their Applications, 18, 81-98.

Aghion, P., and P. Howitt (1992): "A Model of Growth Through Creative Destruction," Econometrica, 60(2), 323-351.

(1998): Endogenous Growth Theory. MIT Press, Cambridge, Massachusetts.

Bassan, B., E. Çinlar, and M. Scarsini (1993): "Stochastic Comparisons of Itô Processes," Stochastic Processes and their Applications, 45, 1-11.

Bellman, R. (1957): Dynamic Programming. Princeton University Press, Princeton.

Cass, D. (1965): "Optimum Growth in an Aggregative Model of Capital Accumulation," Review of Economic Studies, 32, 233-240.

Chang, F.-R. (2004): Stochastic Optimization in Continuous Time. Cambridge University Press, Cambridge.

Dempster, M. A. H. (1991): "Optimal Control of Piecewise Deterministic Markov Processes," in Applied Stochastic Analysis, ed. by M. H. A. Davis, and R. J. Elliott, pp. 303-325. Gordon and Breach, New York.

Dixit, A. K., and R. S. Pindyck (1994): Investment Under Uncertainty. Princeton University Press, Princeton.

Duffie, D., W. Fleming, H. M. Soner, and T. Zariphopoulou (1997): "Hedging in Incomplete Markets with HARA Utility," Journal of Economic Dynamics and Control, 21, 753-782.

Framstad, N. C., B. Øksendal, and A. Sulem (2001): "Optimal Consumption and Portfolio in a Jump Diffusion Market with Proportional Transaction Costs," Journal of Mathematical Economics, 35, 233-257.

García, M. A., and R. J. Griego (1994): "An Elementary Theory of Stochastic Differential Equations Driven by A Poisson Process," Communications in Statistics: Stochastic Models, 10(2), 335-363. 
Gihman, I. I., and A. V. Skorohod (1972): Stochastic Differential Equations. Springer-Verlag, New York.

Grossman, G., and E. Helpman (1991): "Quality Ladders in the Theory of Growth," Review of Economic Studies, 58, 43-61.

Kiyotaki, N., and R. Wright (1991): “A Contribution to the Pure Theory of Money," Journal of Economic Theory, 53, $215-235$.

Koopmans, T. C. (1965): "On the Concept of Optimal Growth," in The Econometric Approach to Development Planning. North Holland., Amsterdam.

Kushner, H. J. (1967): Stochastic Stability and Control. Academic Press, London.

Malliaris, A. G., and W. A. Brock (1982): Stochastic Methods in Economics and Finance. North-Holland, Amsterdam.

Merton, R. C. (1969): "Lifetime Portfolio Selection under Uncertainty: The ContinuousTime Case," Review of Economics and Statistics, 51, 247-257.

_ (1971): "Optimum Consumption and Portfolio Rules in a Continuous-Time Model," Journal of Economic Theory, 3, 373-413.

(1990): Continuous-Time Finance. Blackwell Publishers, Oxford.

Moen, E. (1997): "Competitive Search Equilibrium," Journal of Political Economy, 105, 385-411.

Obstfeld, M. (1994): "Risk-Taking, Global Diversification, and Growth," The American Economic Review, 84, 1310-1329.

Øksendal, B. (2000): Stochastic Differential Equations. Springer-Verlag, Berlin.

Protter, P. (1995): Stochastic Integration and Differential Equations. Springer-Verlag, Berlin.

Sandmo, A. (1970): "The Effect of Uncertainty on Saving Decisions," Review of Economic Studies, 37, 353-360. 
Sennewald, K. (2006): "Controlled Stochastic Differential Equations under Poisson Uncertainty and with Unbounded Utility," Revised version of Discussion Paper Series in Economics 03/05, Available at http://www.wifak.uni-wuerzburg.de/vwl2/ks. Invited resubmission at the Journal of Economic Dynamics and Control.

Sennewald, K., and K. Wälde (2006): "Itô's Lemma" and the Bellman Equation for Poisson Processes: An Applied View," Revised version of Discussion Paper Series in Economics 04/05, Available at www.waelde.com/publications.html.

Steger, T. M. (2005): "Stochastic Growth under Wiener and Poisson Uncertainty," Economic Letters, 86, 311-316.

Turnovsky, S. J. (2000): Methods of Macroeconomic Dynamics. MIT Press, Camebridge, Massachusetts.

van der Ploeg, F. (1993): "A Closed-Form Solution for a Model of Precautionary Saving," Review of Economic Studies, 60, 385-395.

Wälde, K. (1999a): “A Model of Creative Destruction with Undiversifiable Risk and Optimising Households," Economic Journal, 109, 156-171.

(1999b): “Optimal Saving under Poisson Uncertainty," Journal of Economic Theory, 87, 194-217.

(2005): "Endogenous Growth Cycles," International Economic Review, 46, 867-894. 


\section{CESifo Working Paper Series}

(for full list see www.cesifo-group.de)

1621 Edward Castronova, On the Research Value of Large Games: Natural Experiments in Norrath and Camelot, December 2005

1622 Annette Alstadsæter, Ann-Sofie Kolm and Birthe Larsen, Tax Effects, Search Unemployment, and the Choice of Educational Type, December 2005

1623 Vesa Kanniainen, Seppo Kari and Jouko Ylä-Liedenpohja, Nordic Dual Income Taxation of Entrepreneurs, December 2005

1624 Lars-Erik Borge and Linn Renée Naper, Efficiency Potential and Efficiency Variation in Norwegian Lower Secondary Schools, December 2005

1625 Sam Bucovetsky and Andreas Haufler, Tax Competition when Firms Choose their Organizational Form: Should Tax Loopholes for Multinationals be Closed?, December 2005

1626 Silke Uebelmesser, To go or not to go: Emigration from Germany, December 2005

1627 Geir Haakon Bjertnæs, Income Taxation, Tuition Subsidies, and Choice of Occupation: Implications for Production Efficiency, December 2005

1628 Justina A. V. Fischer, Do Institutions of Direct Democracy Tame the Leviathan? Swiss Evidence on the Structure of Expenditure for Public Education, December 2005

1629 Torberg Falch and Bjarne Strøm, Wage Bargaining and Political Strength in the Public Sector, December 2005

1630 Hartmut Egger, Peter Egger, Josef Falkinger and Volker Grossmann, International Capital Market Integration, Educational Choice and Economic Growth, December 2005

1631 Alexander Haupt, The Evolution of Public Spending on Higher Education in a Democracy, December 2005

1632 Alessandro Cigno, The Political Economy of Intergenerational Cooperation, December 2005

1633 Michiel Evers, Ruud A. de Mooij and Daniel J. van Vuuren, What Explains the Variation in Estimates of Labour Supply Elasticities?, December 2005

1634 Matthias Wrede, Health Values, Preference Inconsistency, and Insurance Demand, December 2005

1635 Hans Jarle Kind, Marko Koethenbuerger and Guttorm Schjelderup, Do Consumers Buy Less of a Taxed Good?, December 2005 
1636 Michael McBride and Stergios Skaperdas, Explaining Conflict in Low-Income Countries: Incomplete Contracting in the Shadow of the Future, December 2005

1637 Alfons J. Weichenrieder and Oliver Busch, Artificial Time Inconsistency as a Remedy for the Race to the Bottom, December 2005

1638 Aleksander Berentsen and Christopher Waller, Optimal Stabilization Policy with Flexible Prices, December 2005

1639 Panu Poutvaara and Mikael Priks, Violent Groups and Police Tactics: Should Tear Gas Make Crime Preventers Cry?, December 2005

1640 Yin-Wong Cheung and Kon S. Lai, A Reappraisal of the Border Effect on Relative Price Volatility, January 2006

1641 Stefan Bach, Giacomo Corneo and Viktor Steiner, Top Incomes and Top Taxes in Germany, January 2006

1642 Johann K. Brunner and Susanne Pech, Optimum Taxation of Life Annuities, January 2006

1643 Naércio Aquino Menezes Filho, Marc-Andreas Muendler and Garey Ramey, The Structure of Worker Compensation in Brazil, with a Comparison to France and the United States, January 2006

1644 Konstantinos Angelopoulos, Apostolis Philippopoulos and Vanghelis Vassilatos, RentSeeking Competition from State Coffers: A Calibrated DSGE Model of the Euro Area, January 2006

1645 Burkhard Heer and Bernd Suessmuth, The Savings-Inflation Puzzle, January 2006

1646 J. Stephen Ferris, Soo-Bin Park and Stanley L. Winer, Political Competition and Convergence to Fundamentals: With Application to the Political Business Cycle and the Size of Government, January 2006

1647 Yu-Fu Chen, Michael Funke and Kadri Männasoo, Extracting Leading Indicators of Bank Fragility from Market Prices - Estonia Focus, January 2006

1648 Panu Poutvaara, On Human Capital Formation with Exit Options: Comment and New Results, January 2006

1649 Anders Forslund, Nils Gottfries and Andreas Westermark, Real and Nominal Wage Adjustment in Open Economies, January 2006

1650 M. Hashem Pesaran, Davide Pettenuzzo and Allan G. Timmermann, Learning, Structural Instability and Present Value Calculations, January 2006

1651 Markku Lanne and Helmut Luetkepohl, Structural Vector Autoregressions with Nonnormal Residuals, January 2006 
1652 Helge Berger, Jakob de Haan and Jan-Egbert Sturm, Does Money Matter in the ECB Strategy? New Evidence Based on ECB Communication, January 2006

1653 Axel Dreher and Friedrich Schneider, Corruption and the Shadow Economy: An Empirical Analysis, January 2006

1654 Stefan Brandauer and Florian Englmaier, A Model of Strategic Delegation in Contests between Groups, January 2006

1655 Jan Zápal and Ondřej Schneider, What are their Words Worth? Political Plans and Economic Pains of Fiscal Consolidations in New EU Member States, January 2006

1656 Thiess Buettner, Sebastian Hauptmeier and Robert Schwager, Efficient Revenue Sharing and Upper Level Governments: Theory and Application to Germany, January 2006

1657 Daniel Haile, Abdolkarim Sadrieh and Harrie A. A. Verbon, Cross-Racial Envy and Underinvestment in South Africa, February 2006

1658 Frode Meland and Odd Rune Straume, Outsourcing in Contests, February 2006

1659 M. Hashem Pesaran and Ron Smith, Macroeconometric Modelling with a Global Perspective, February 2006

1660 Alexander F. Wagner and Friedrich Schneider, Satisfaction with Democracy and the Environment in Western Europe - a Panel Analysis, February 2006

1661 Ben J. Heijdra and Jenny E. Ligthart, Fiscal Policy, Monopolistic Competition, and Finite Lives, February 2006

1662 Ludger Woessmann, Public-Private Partnership and Schooling Outcomes across Countries, February 2006

1663 Topi Miettinen and Panu Poutvaara, Political Parties and Network Formation, February 2006

1664 Alessandro Cigno and Annalisa Luporini, Optimal Policy Towards Families with Different Amounts of Social Capital, in the Presence of Asymmetric Information and Stochastic Fertility, February 2006

1665 Samuel Muehlemann and Stefan C. Wolter, Regional Effects on Employer Provided Training: Evidence from Apprenticeship Training in Switzerland, February 2006

1666 Laszlo Goerke, Bureaucratic Corruption and Profit Tax Evasion, February 2006

1667 Ivo J. M. Arnold and Jan J. G. Lemmen, Inflation Expectations and Inflation Uncertainty in the Eurozone: Evidence from Survey Data, February 2006

1668 Hans Gersbach and Hans Haller, Voice and Bargaining Power, February 2006 
1669 Françoise Forges and Frédéric Koessler, Long Persuasion Games, February 2006

1670 Florian Englmaier and Markus Reisinger, Information, Coordination, and the Industrialization of Countries, February 2006

1671 Hendrik Hakenes and Andreas Irmen, Something out of Nothing? Neoclassical Growth and the 'Trivial' Steady State, February 2006

1672 Torsten Persson and Guido Tabellini, Democracy and Development: The Devil in the Details, February 2006

1673 Michael Rauber and Heinrich W. Ursprung, Evaluation of Researchers: A Life Cycle Analysis of German Academic Economists, February 2006

1674 Ernesto Reuben and Frans van Winden, Reciprocity and Emotions when Reciprocators Know each other, February 2006

1675 Assar Lindbeck and Mats Persson, A Model of Income Insurance and Social Norms, February 2006

1676 Horst Raff, Michael Ryan and Frank Staehler, Asset Ownership and Foreign-Market Entry, February 2006

1677 Miguel Portela, Rob Alessie and Coen Teulings, Measurement Error in Education and Growth Regressions, February 2006

1678 Andreas Haufler, Alexander Klemm and Guttorm Schjelderup, Globalisation and the Mix of Wage and Profit Taxes, February 2006

1679 Kurt R. Brekke and Lars Sørgard, Public versus Private Health Care in a National Health Service, March 2006

1680 Dominik Grafenhofer, Christian Jaag, Christian Keuschnigg and Mirela Keuschnigg, Probabilistic Aging, March 2006

1681 Wladimir Raymond, Pierre Mohnen, Franz Palm and Sybrand Schim van der Loeff, Persistence of Innovation in Dutch Manufacturing: Is it Spurious?, March 2006

1682 Andrea Colciago, V. Anton Muscatelli, Tiziano Ropele and Patrizio Tirelli, The Role of Fiscal Policy in a Monetary Union: Are National Automatic Stabilizers Effective?, March 2006

1683 Mario Jametti and Thomas von Ungern-Sternberg, Risk Selection in Natural Disaster Insurance - the Case of France, March 2006

1684 Ken Sennewald and Klaus Waelde, "Itô's Lemma" and the Bellman Equation for Poisson Processes: An Applied View, March 2006 